\title{
A Novel Transcriptional Factor Important for Pathogenesis and Ascosporogenesis in Fusarium graminearum
}

\author{
Yang Wang, ${ }^{1,2}$ Wende Liu, ${ }^{2}$ Zhanming Hou, ${ }^{2}$ Chenfang Wang, ${ }^{1}$ Xiaoying Zhou, ${ }^{2}$ Wilfried Jonkers, ${ }^{3}$ \\ Shengli Ding, ${ }^{2} \mathrm{H}$. Corby Kistler, ${ }^{3}$ and Jin-Rong $\mathrm{Xu}^{1,2}$ \\ ${ }^{1}$ College of Plant Protection, Northwest A\&F University, Yangling, Shaanxi 712100, China; ${ }^{2}$ Department of Botany and Plant \\ Pathology, Purdue University, West Lafayette, IN 47907, U.S.A.; ${ }^{3}$ United States Department of Agriculture-Agricultural \\ Research Service Cereal Disease Laboratory, University of Minnesota, St. Paul 55108, U.S.A.
}

Submitted 4 June 2010. Accepted 22 August 2010.

Fusarium head blight or scab caused by Fusarium graminearum is an important disease of wheat and barley. The pathogen not only causes severe yield losses but also contaminates infested grains with mycotoxins. In a previous study, we identified several pathogenicity mutants by random insertional mutagenesis. One of these mutants was disrupted in the ZIF1 gene, which encodes a b-ZIP transcription factor unique to filamentous ascomycetes. The $\Delta z$ if 1 mutant generated by gene replacement was significantly reduced in deoxynivalenol (DON) production and virulence on flowering wheat heads. It was defective in spreading from inoculated florets to the rachis and other spikelets. Deletion of the ZIF1 ortholog MoZIF1 in the rice blast fungus also caused reductions in virulence and in invasive growth. In addition, the $\Delta z$ if 1 mutant is defective in sexual reproduction. Although it had normal male fertility, when selfed or mated as the female in outcrosess, the $\Delta z i f 1$ mutant produced small, pigmented perithecia that were sterile (lack of asci and ascospores), suggesting a female-specific role for ZIF1 during fertilization or ascus development. Similar female-specific defects in sexual reproduction were observed in the $\Delta$ Mozif1 mutant. When mated as the female, the $\Delta M o z i f 1$ perithecia failed to develop long necks and asci or ascospores. The ZIF1 gene is well conserved in filamentous ascomycetes, particularly in the b-ZIP domain, which is essential for its function. Expression of ZIF1 in Magnaporthe oryzae complemented the defects of the $\Delta M o z i f 1$ mutant. These results indicate that this b-ZIP transcription factor is functionally conserved in these two fungal pathogens for plant infection and sexual reproduction.

Fusarium graminearum (teleomorph Gibberella zeae) infects wheat, barley, maize, and other crop plants (Bai and Shaner 2004; Goswami and Kistler 2004). In North America, it is the predominant species causing scab or head blight of wheat and barley. In addition to yield losses caused by this pathogen, infested cereals often are contaminated with deoxynivalenol (DON) and other toxins that are harmful to human and animals (Walter et al. 2010). F. graminearum overwinters in plant debris and infects susceptible floral tissues with ascospores as the primary inoculum (Schmale et al. 2005; Trail et al. 2002,

Corresponding author: Jin-Rong Xu; Telephone: +1.765 .496 .6918 ; Fax: +1.765.494.0363; E-mail: jinrong@ @ purdue.edu

* The $\boldsymbol{e}$-Xtra logo stands for "electronic extra" and indicates that Figures 2 and 5 are published in color online and four supplementary figures and three supplementary tables are published online.
2005). Infection of wheat heads is initiated when ascospores are deposited on or inside flowering spikelets, which can occur from the beginning of anthesis to the dough stage of kernel development. The fungus then spreads from the infected floret to the rachis and causes severe damage under conducive environmental conditions.

The first pathogenicity factor characterized in $F$. graminearum is the trichodiene synthase gene, TRI5, which is essential for DON production and spreading within colonized wheat heads (Bai et al. 2002; Proctor et al. 1995). In the past two decades, the trichothecene biosynthesis pathway has been extensively studied in Fusarium spp. In $F$. graminearum, most genes encoding regulatory or transporter proteins and enzymes for metabolic steps in DON biosynthesis have been well characterized, including TRI3, TRI4, TRI5, TRI6, TRI7, TRI10, and TRI101 (Alexander et al. 2009; Desjardins, 2003; Seong et al. 2009). TRI6 and TRIIO are pathway-specific transcriptional regulators of the TRI clusters. Although it is not clear what plant factors stimulate the fungus to synthesize trichothecenes, there are studies on environmental conditions and chemical compounds that induce DON production in axenic cultures (Audenaert et al. 2010; Gardiner et al. 2009ab).

In the past few years, a variety of genetic and genomic resources have been accumulated for $F$. graminearum, including $10 \times$ coverage of the genome sequence (Cuomo et al. 2007) and a whole-genome Affymetrix GeneChip (Guldener et al. 2006). The availability of these resources has significantly advanced or benefited genetic studies on molecular mechanisms regulating plant infection and fungus-plant interactions in this important pathogen (Goswami and Kistler 2004; Trail 2009; Walter et al. 2010). To date, genes with various biological or biochemical functions have been shown to be important for plant infection and spreading in $F$. graminearum, such as the Cid1 type $\mathrm{C}$ cyclin (Zhou et al. 2010), FgPtc1 type 2C protein phosphatase (Jiang et al. 2010), chitin synthases (Kim et al. 2009), and topoisomerase (Baldwin et al. 2010). Components of and genes regulated by conserved signaling pathways are among the best-studied pathogenicity factors in $F$. graminearum (Hou et al. 2002; Jenczmionka and Schafer 2005; Jenczmionka et al. 2003; Urban et al. 2003; Yu et al. 2008). A number of genes related to primary metabolism, including CBL1, MSY1, HMR1, NPS6, and CPS1, also have been shown to be required for virulence (Lee et al. 2009a and b; Oide et al. 2006; Seong et al. 2005, 2006).

In a previous study, we used the restriction enzyme-mediated integration (REMI) insertional mutagenesis approach to generate mutants with reduced or lost virulence (Seong et al. 2005). One of these mutants was disrupted in the ZIF1 gene 
that encodes a putative b-ZIP transcription factor unique to filamentous ascomycetes. In this study, we generated and characterized the $\Delta z$ ifl mutant. Like REMI mutant M7, the $\Delta z$ ifl mutant was significantly reduced in DON production and virulence on flowering wheat heads. It also displayed female-specific defects in sexual reproduction. Similar defects in plant infection and female fertility were observed in the Magnaporthe oryzae mutant deleted from the ZIF1 ortholog. Zif1 is well conserved in the class Sordariomycetes but none of its orthologs have been characterized in other fungi. Results from this study indicate that ZIF1 may be conserved in fungal pathogens for female fertility and invasive growth after penetration or initial colonization.

\section{RESULTS}

\section{The ZIF1 gene is disrupted in REMI mutant M7.}

REMI mutant M7 was generated in a previous study by transforming the EcoRI-digested plasmid vector pKY37 into the wild-type strain PH-1 (Seong et al. 2005). It had reduced virulence on flowering wheat heads. The conventional plasmid rescue approach was used to identify the flanking sequence of the integrated pKY37. Plasmid pMS7 containing a 3.8-kb genomic fragment (Fig. 1A) was isolated and sequenced. Sequencing analysis revealed that the transforming vector $\mathrm{pKY} 37$ was inserted in the EcoRI site located in the predicted gene FGSG_01555.3 (Fig. 1A). This gene, named ZIF1 (for bZIP transcription factor 1) in this study, encodes a 568-amino acid protein with a basic-leucine zipper (bZIP) domain. It has no distinct homolog in the budding or fission yeast but is conserved in filamentous ascomycetes (Supplementary Fig. 1). However, none of the ZIFI orthologs have been functionally characterized in other fungi. Except for the bZIP domain, there is no other known domain or motif in the Zif1 protein. Nevertheless, the glutamine-rich regions adjacent to the bZIP domain are conserved in different fungi and may function in mediating protein-protein interactions and transcriptional activation (Escher et al. 2000).

\section{Deletion of the ZIF1 gene has no effect on conidiation or conidium morphology.}

Because the disrupted ZIF1 in mutant M7 may be not a null allele, we generated the ZIF1 gene replacement construct (Fig. 1A) by the split-marker approach (Catlett et al. 2003). After transforming protoplasts of $\mathrm{PH}-1$, putative $\Delta$ zifl mutants were identified by polymerase chain reaction (PCR) and confirmed by Southern blot hybridization (Fig. 1B). When hybridized with a ZIF1 fragment amplified with primers BTN-1F and BTN-2R, the wild-type and ectopic transformants had the 6.3$\mathrm{kb}$ PstI band. The $\Delta$ zifl mutant ZP10 had no hybridization signals (Fig. 1B). Similar to REMI mutant M7, ZP10 had a slight reduction in the growth rate (Table 1) but it had no defects in conidiation, conidium morphology, and germination.

\section{The $\Delta z i f 1$ mutant has reduced virulence.}

In infection assays with flowering wheat heads, the $\Delta z$ if 1 mutant usually only caused typical scab symptoms on the inoculated florets 14 days postinoculation (dpi). Symptoms rarely spread to nearby spikelets on the same wheat heads (Fig. 2A). The average disease index of the $\Delta z i f 1$ mutant was approximately 1 (Table 1). Under the same conditions, the wild type and the ectopic transformant spread from the inoculated florets to nearby spikelets. The disease index for the wild-type and ectopic transformant was $>6$ (Table 1), indicating that the $\Delta z i f 1$ mutant was significantly reduced in virulence on wheat.

Because $F$. graminearum also is a corn pathogen, we assayed the virulence of mutants M7 and ZP10 on corn stalks and silks.
In plants inoculated with the wild type and an ectopic transformant, areas of stalk rot often extended from the inoculation site to or close to the nodes above and below $14 \mathrm{dpi}$ (Fig. 2B). In contrast, $\Delta z i f 1$ mutants caused only limited stalk rot in inoculated corn piths (Fig. 2B). Lack of extensive spreading in corn pith tissues indicates that ZIFI is a virulence factor for stalk rot. Mutants M7 and ZP10 also were significantly reduced in virulence in corn silk infection assays (data not shown).

Similar defects of mutants M7 and ZP10 in growth and plant infection suggested that disruption or deletion of the ZIFI gene was responsible for the observed phenotypes. To further confirm this observation, we reintroduced the full-length ZIFI gene into protoplasts of ZP10. Bcom9 (Table 2) was one of the resulting geneticin-resistant transformants that contained a single copy of the transforming complementation construct (data not shown). Bcom9 had the wild-type growth rate and virulence (Table 1; Fig. 2A), indicating that the reintroduced ZIF1 allele complemented the $\Delta z i f 1$ mutant. We also generated the $Z I F 1^{\Delta b Z I P}$ allele deleted from the entire b-ZIP domain (amino acids 276 to 339) and transformed it into ZP10. Several transformants, including YP6 and YP8, were confirmed by Southern analysis to contain the transforming $Z I F 1^{\triangle \mathrm{bZIP}}$ construct. However, these $Z I F 1^{\triangle \mathrm{bZIP}}$ transformants had phenotypes similar to that of the original $\Delta z$ ifl mutant, indicating that the b-ZIP domain is essential for ZIF1 function.

\section{Ascus and ascospore formation are blocked in the $\Delta z$ if 1 mutant.}

We assayed mating and ascospore production in the $\Delta z$ ifl mutant because ascospores are the primary inoculum in $F$. graminearum. At 7 days after fertilization, the $\Delta$ zifl mutant formed smaller and fewer perithecia than the wild type on carrot agar plates (Fig. 3A). When examined under a microscope, abundant asci and ascospores were visible in perithecia formed by the wild type but not in $\Delta$ zifl mutant perithecia (Fig. 3A).

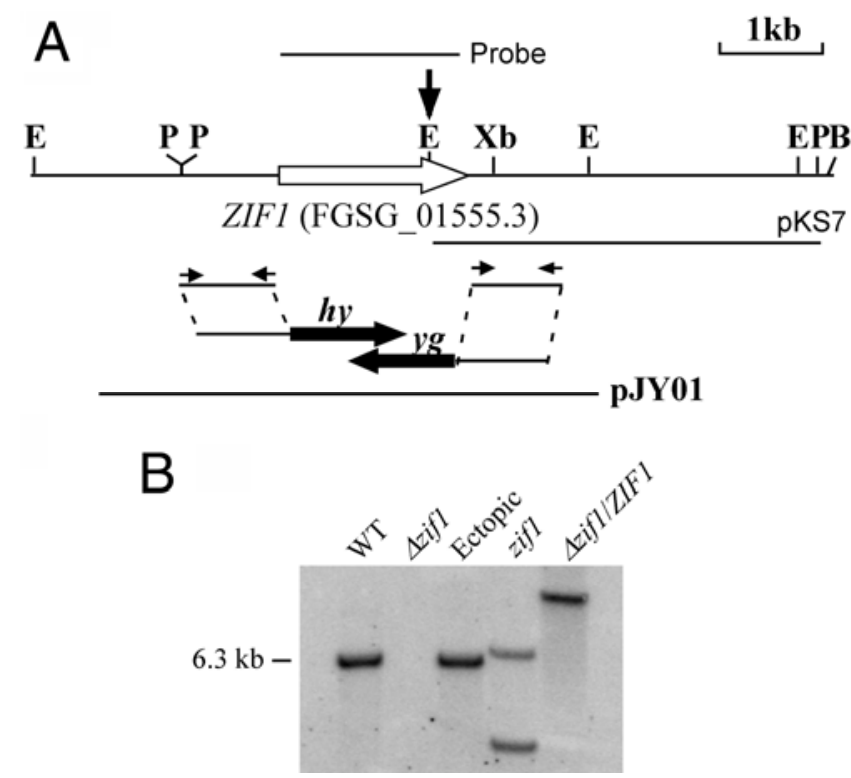

Fig. 1. ZIF1 gene and generation of the $\triangle z$ ifl mutant. A, Schematic drawing of the ZIF1 locus. The insertion site of transforming vector in the ZIF 1 gene was marked with a vertical black arrow. Plasmid pKS7 was recovered by plasmid rescue from mutant M7. Plasmid pJY01 was used for complementation assays. Smaller arrows represented primers used for generating the $\Delta z i f 1$ mutant. B, BamHI; E, EcoRI; P, PstI; Xb, XbaI. B, Southern blot analysis of PstI-digested genomic DNA of the wild type (WT) PH-1, $\Delta$ zifl mutant ZP10, ectopic transformant ZP4, REMI mutant M7 (zif1), and complemented transformant Bcom9. The probe was amplified with primers $\mathrm{bZF} 1 \mathrm{~F}$ and $\mathrm{bZF} 2 \mathrm{R}$. 
When matured, the wild-type perithecia oozed out ascospores and formed cirrhi at the ostiole (Fig. 3B). Perithecia produced by the $\Delta z$ ifl mutant failed to enlarge and form cirrhi even after incubation for 21 days or longer (Fig. 3B).

When examined by transmission electronic microscopy, ascospores and asci were visible in the perithecia formed by $\mathrm{PH}-1$ 7 days after fertilization. In contrast, no ascospores were observed in perithecia of the $\Delta$ zifl mutant (Fig. 3C). These data indicate that, although it is dispensable for protoperithecium or perithecium formation, ZIF1 must play a critical role in the late events of ascocarp development and formation of asci and ascospores in selfing crosses $(\Delta z i f 1 \times \Delta z i f 1)$.

\section{ZIF1 is dispensable for male fertility in outcrosses.}

Although it is a homothallic fungus, $F$. graminearum also can outcross. When the zifl mutant ZP10 $\left(\right.$ hyg $\left.{ }^{\mathrm{R}}\right)$ was crossed with a nit1 mutant 11622 that is resistant to potassium chlorate (Hou et al. 2002), mature perithecia with cirrhi were formed on the 11622 side of the confrontation zone 2 to 3 weeks after fertilization. By screening through cirrhi from 50 perithecia, we identified 2 perithecia that produced recombinant nitl hyg ${ }^{\mathrm{R}}$ progeny resistant to both potassium chlorate and hygromycin at $150 \mu \mathrm{g} / \mathrm{ml}$. From these two outcrossing perithecia, we isolated 35 hygromycin-resistant progeny. All of them displayed characteristic phenotypes of the $\Delta z i f 1$ mutant, including reduced virulence and defects in sexual reproduction (data not shown). When grown on potassium chlorate-amended complete medium (CM), 18 progeny failed to grow and, therefore, were determined to be NIT1, whereas 17 progeny grew on the medium and, therefore, were determined to be nitl. These data indicated a 1:1 segregation at the NIT1 locus. Therefore, we conclude that the observed defects of the $\Delta$ zifl mutant but not nitl cosegregated with the $h p h$ marker. Because the $\Delta z i f 1$ mutant was sterile in selfing crosses, the fertility of the ZIF1 $+\times \Delta z$ ifl ${ }^{*}$ cross indicates that ZIFI is dispensable for male fertility but plays a critical role in female fertility.

\section{DON production is reduced in the $\Delta z$ if1 mutant.}

Because of its importance in $F$. graminearum pathogenesis, DON production was measured in diseased wheat kernels from inoculated wheat florets 14 dpi. On average, kernels from wildtype-inoculated heads contained DON at $500 \mathrm{ppm}$, whereas
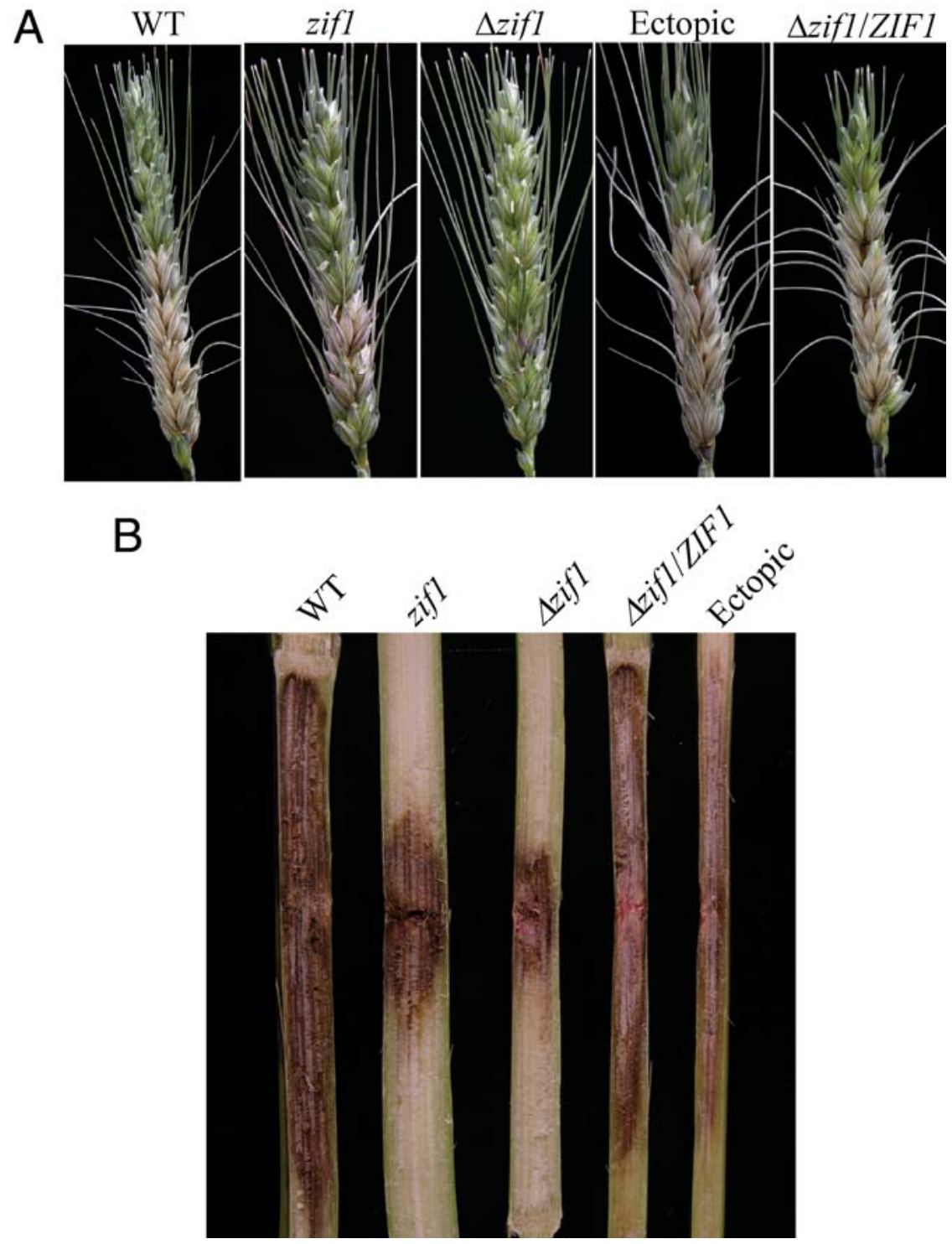

Fig. 2. Wheat head and corn stalk rot infection assays. A, Flowering wheat heads were inoculated with conidia from the wild type (WT) PH-1, REMI mutant M7 (zif1), $\Delta z i f 1$ mutant ZP10, ectopic transformant ZP4, and complemented strain Bcom9. Typical wheat heads were photographed 14 days postinoculation (dpi). B, Corn stalks were inoculated with toothpicks carrying conidia from PH-1, ZP10, ZP4, and Bcom9. Infected corn stalks were split longitudinally at the inoculation sites and examined $14 \mathrm{dpi}$. 
kernels from $\Delta$ zifl mutant-inoculated heads contained fourfold less DON (Table 1). The complemented transformant Bcom9 produced similar amount of DON in infested wheat kernels (Table 1).

We then assayed DON production in axenic cultures as described (Gardiner et al. 2009a). In agmatine cultures, the $\Delta z$ ifl mutant was reduced more than 15 -fold in DON production compared with the wild type (Table 1). DON production was increased in the complemented strain Bcom9 (Table 1), suggesting the involvement of ZIF1 in regulating trichothecene synthesis. To further confirm this observation, we assayed the expression of several TRI genes (Kimura et al. 2007) in agmatine cultures. In the $\Delta$ zifl mutant, the expression level of TRI5 and TRI6 was reduced more than sixfold (Fig. 4A). TRI5 encodes the key enzyme for DON synthesis and TRI6 encodes a major transcriptional regulator of DON synthesis (Seong et al. 2009). For the other TRI genes assayed, TRI4 and TRII2 had no obvious changes but TRI8 and TRII4 also had reduced expression levels in the $\Delta z i f 1$ mutant (Fig. 4A). Interestingly, TRI3 expression was increased approximately twofold in the $\Delta z$ ifl mutant. These data confirmed that deletion of ZIF1 reduced the expression of the key structural and regulatory genes of DON synthesis. However, unlike the TRI-cluster-specific transcription factor Tri6 (Seong et al. 2009), Zif1 appears to have different regulatory effects on various $T R I$ genes.

\section{Expression of the ZIF1 gene.}

The ZIF1-eGFP (enhanced green fluorescent protein) fusion construct under its native promoter control was transformed into the $\Delta z$ ifl mutant ZP10. The resulting transformant NP18 was normal in growth, sexual reproduction, and virulence (data not shown), indicating that the $\mathrm{P}_{\mathrm{ZIF} 1}$-ZIF1-EGFP construct complemented the defects of the $\Delta z i f 1$ mutant. However, we failed to observe GFP signals in vegetative hyphae, conidia, and young perithecia. Zif1-eGFP fusion proteins may be relatively unstable and only transiently localized to the nucleus.

We then assayed ZIF1 expression by quantitative reverse-transcription (qRT)-PCR assays with RNA isolated from different culture conditions or plant infection stages. The expression level of ZIF1 was relatively low in freshly harvested conidia and young germlings $(10 \mathrm{~h})$ but increased in mature vegetative hyphae (Fig. 4B). The highest expression level was in developing perithecia (5 days postfertilization). These results were consistent with the defects of $\Delta z i f 1$ mutant in ascospore production. According to microarray data deposited in the PLEXdb database, ZIF1 also is upregulated during barley infection (Boddu et al. 2006), indicating that it may be involved in plant infection.

\section{ZIF1 is important for spreading to the rachis.}

To visualize fungal growth in infected plant tissues, we transformed the RP27-GFP construct pRM7 (Mehrabi et al. 2008) into protoplasts of $\mathrm{PH}-1$ and $\mathrm{ZP} 10$. The resulting transformants, RM7PH1 and RM7zp10 (Table 1), had strong GFP signals in the cytoplasm of conidia and vegetative hyphae. In wheat heads inoculated with RM7PH1, extensive fungal growth was visible in the rachis tissues next to the inoculated site $5 \mathrm{dpi}$ (Fig. 5). Under the same conditions, hyphal growth of the $\Delta z i f 1$ mutant failed to spread from the inoculated floret to the rachis. GFP signals were only observed at the site (likely the scission zone) where the inoculated floret was removed (Fig. 5). These data indicate that the $\Delta z$ ifl mutant colonized the inoculated floret but its spread to the rachis and other spikelets was restricted, which may explain the reduced virulence of the $\Delta$ zifl mutant (Table 1).

\section{The $\Delta z$ if1 mutant was hypersensitive to reactive oxygen species.}

When assayed for growth on CM, the $\Delta z i f 1$ mutant had no obvious changes in sensitivities to $1 \mathrm{M}$ sorbitol, $0.7 \% \mathrm{NaCl}$,

Table 1. Growth, conidiation, deoxynivalenol (DON) production, and virulence of Fusarium graminearum strains

\begin{tabular}{|c|c|c|c|c|c|}
\hline \multirow[b]{2}{*}{ Strain } & \multirow[b]{2}{*}{ Growth rate $(\mathrm{mm} / \mathrm{day})^{\mathrm{a}}$} & \multirow[b]{2}{*}{ Conidiation $\left(\times 10^{5}\right.$ spores $\left./ \mathrm{ml}\right)$} & \multicolumn{2}{|c|}{ DON (ppm) } & \multirow[b]{2}{*}{ Disease index ${ }^{\mathrm{d}}$} \\
\hline & & & Infected kernels $^{\mathrm{b}}$ & Axenic cultures ${ }^{c}$ & \\
\hline PH-1 & $11.5 \pm 0.5$ & $42.1 \pm 0.9$ & $505.0 \pm 249.3$ & $2,410.1 \pm 100.0$ & $6.8 \pm 1.2$ \\
\hline ZP10 & $10.5 \pm 0.0$ & $39.5 \pm 3.9$ & $117.0 \pm 68.4$ & $137.7 \pm 61.4$ & $0.6 \pm 0.2$ \\
\hline Bcom9 & $12.0 \pm 0.5$ & $26.3 \pm 3.2$ & $530.0 \pm 86.1$ & $1,026.8 \pm 233.3$ & $5.9 \pm 1.9$ \\
\hline M7 & $9.5 \pm 0.5$ & $62.2 \pm 4.6$ & $205.3 \pm 46.1$ & $483.8 \pm 123.8$ & $1.6 \pm 1.4$ \\
\hline
\end{tabular}

${ }^{a}$ Average and standard deviation of daily extension in colony radius during 5 days of growth on $\mathrm{V} 8$ agar in $\Phi 15$-cm petri plates at $25^{\circ} \mathrm{C}$.

${ }^{\mathrm{b}}$ DON production in infected wheat kernels harvested from inoculated wheat heads 14 days postinoculation. Mean and standard deviation were calculated from four independent infection assays.

${ }^{\mathrm{c}}$ DON production in the defined medium with $0.2 \%$ agmatine.

${ }^{\mathrm{d}}$ Mean and standard deviation of diseased spikelets per wheat head.

Table 2. Fusarium graminearum and Magnaporthe oryzae strains used in this study

\begin{tabular}{|c|c|c|}
\hline Strain & Brief description & Reference \\
\hline \multicolumn{3}{|c|}{ F. graminearum } \\
\hline PH-1 & Wild-type & Trail et al. 2003 \\
\hline 11622 & nit1 mutant of PH-1 & Hou et al. 2002 \\
\hline M7 & REMI mutant disrupted in the ZIF1 gene & Seong et al. 2005 \\
\hline ZP10 & $\Delta z i f 1$ gene replacement mutant & This study \\
\hline ZP4 & An ectopic knockout mutant & This study \\
\hline Bcom9 & Complemented transformant of ZP10 ( $\triangle z$ if $1 / Z I F 1)$ & This study \\
\hline NP18 & Transformant of ZP10 expressing $\mathrm{P}_{\mathrm{ZIF1} 1}-Z I F 1$-eGFP & This study \\
\hline YP6 & Transformant of ZP10 expressing the ZIF $1^{\Delta \mathrm{BZIP}}$ allele & This study \\
\hline YP8 & Transformant of ZP10 expressing the ZIF $1^{\Delta \mathrm{bZIP}}$ allele & This study \\
\hline RM7PH1 & Transformant of PH-1 expressing $\mathrm{P}_{\mathrm{RP} 27}$-eGFP (pRM7) & This study \\
\hline RM7zp10 & Transformant of ZP10 expressing $\mathrm{P}_{\mathrm{RP} 27}$-eGFP (pRM7) & This study \\
\hline \multicolumn{3}{|c|}{ - } \\
\hline Guy11 & Wild-type (MAT1-2, avr-Pita) & Chao and Ellingboe 1991 \\
\hline $70-15$ & Wild-type (MAT1-1, AVR-Pita) & Chao and Ellingboe 1991 \\
\hline bzip24 & $\Delta$ Mozif1 mutant of $70-15$ (MAT1-1) & This study \\
\hline MFC1 & Transformant of bzip24 expressing $\mathrm{P}_{\mathrm{ZIF} 1}-\mathrm{ZIF1- \textrm {eGFP }}$ & This study \\
\hline
\end{tabular}


Congo red at $200 \mu \mathrm{g} / \mathrm{ml}$, or $0.01 \%$ sodium dodecyl sulfate (SDS), indicating that ZIF1 is not involved in response to hyperosmotic and cell wall stresses. However, deletion of ZIFI resulted in increased sensitivity to $\mathrm{H}_{2} \mathrm{O}_{2}$. In the presence of $0.08 \% \mathrm{H}_{2} \mathrm{O}_{2}$, the $\Delta$ zifl mutant had no visible growth but the wild type and complemented transformants still formed colonies (Supplementary Fig. 2).

The ZIF1 ortholog is important for virulence in M. oryzae.

To determine whether the function of ZIF1 in plant infection is conserved in other fungi, we generated the gene replacement mutant of MGG_03288.6, which was orthologous to ZIF1 (named MoZIF1 in this study). The $\Delta$ Mozifl mutant (Supplementary Fig. 3) was normal in vegetative growth, conidiation, and appressorium formation (data not shown). However, its virulence was reduced in infection assays with rice seedlings (Fig. 6A). When assayed for appressorial penetration with onion epidermal cells, the $\Delta$ Mozifl mutant had reduced growth of infectious hyphae compared with the wild type (Fig. 6B). These results indicate that MoZIF1 is important for invasive growth and lesion development in $M$. oryzae.
A
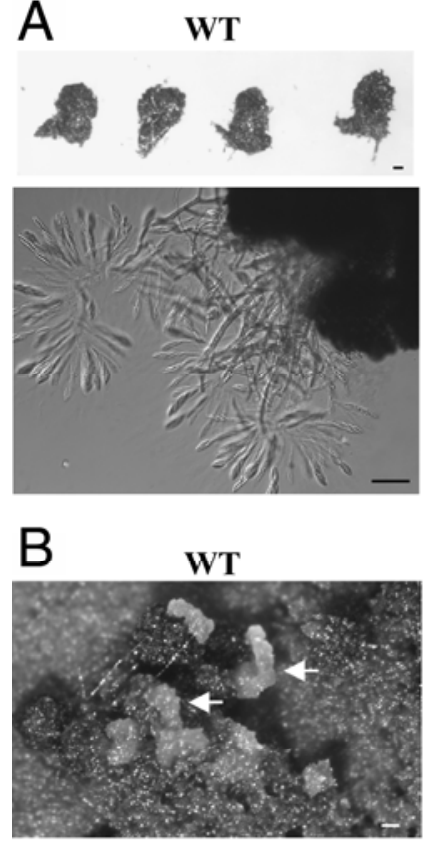

C

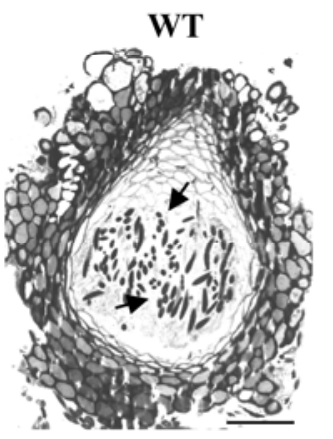

$\Delta z$ if 1
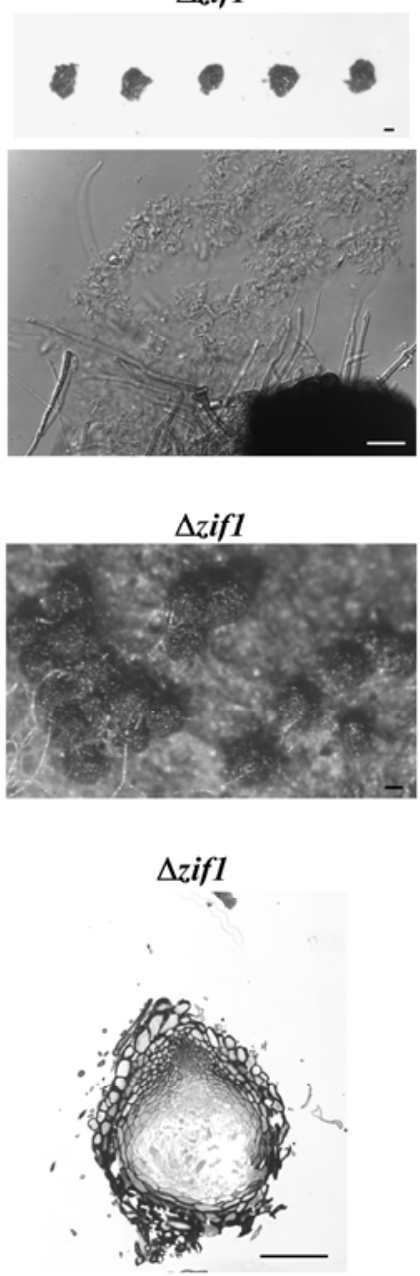

Fig. 3. The $\Delta z i f 1$ mutant was defective in sexual reproduction. A, Representative perithecia of the wild type (WT) PH-1 and $\Delta z i f 1$ mutant (ZP10) were examined under a dissecting (upper panels) or compound (lower panels) microscope 10 days after fertilization. Fascicles of asci were observed in PH-1 but not in ZP10. B, Ascospores oozed from mature perithecia as cirrhi (marked with arrows) in the WT but not mutant perithecia 14 days after fertilization. C, Perithecia of PH-1 and ZP10 were examined by transmission electron microscopy. Arrows point to asci and ascospores. $\operatorname{Bar}=50 \mu \mathrm{m}$.
MoZIF1 also is essential for female fertility.

In $M$. oryzae, perithecia are normally embedded within the substrate but develop long beaks that protrude from the surface of the substrate and through which ascospores are released.
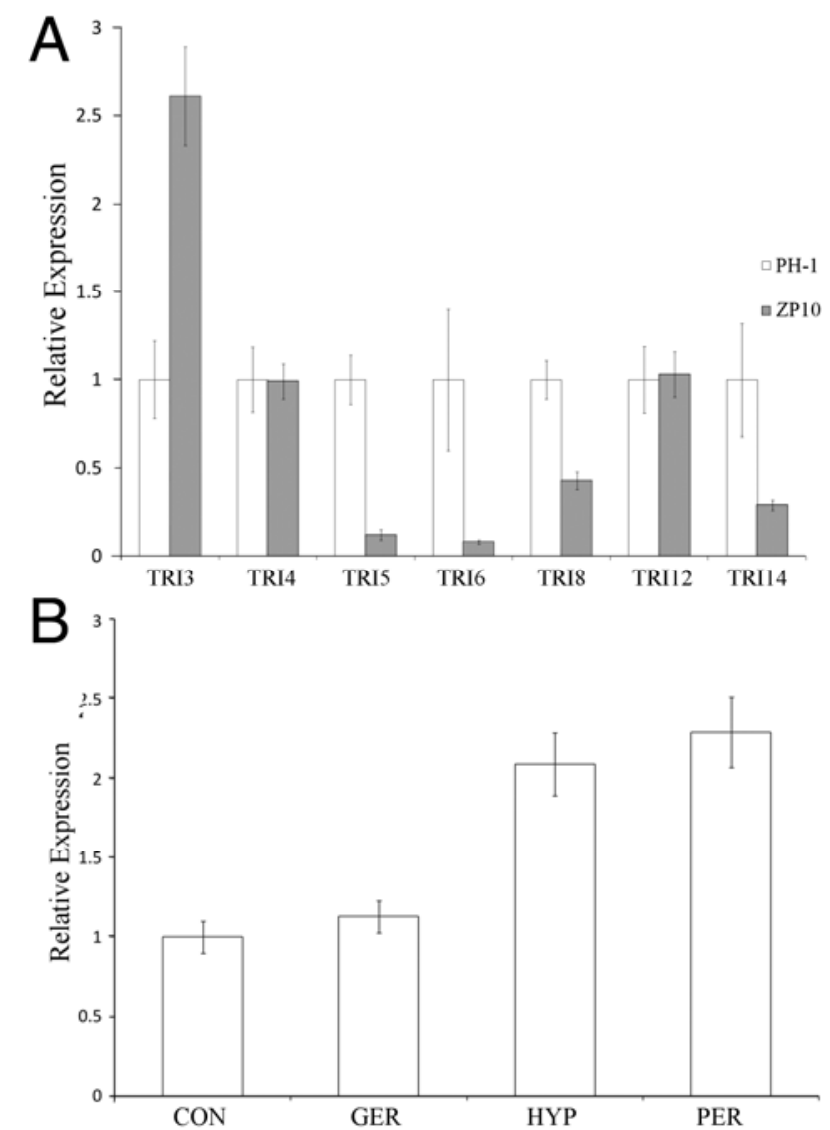

Fig. 4. Quantitative reverse-transcription polymerase chain reaction analyses of the TRI and ZIFI genes. A, Expression levels of selected TRI genes in the wild type (WT) and $\Delta z i f 1$ mutant. RNA was isolated from agmatine cultures. For each gene, its relative expression in the WT was normalized to the value 1. B, Expression of ZIF1 in freshly harvested conidia (5-day-old CMC cultures), germlings ( $10 \mathrm{~h}$ in complete medium $[\mathrm{CM}]$ ), vegetative hyphae (36 $\mathrm{h}$ CM cultures), and developing perithecia (5 days after fertilization).
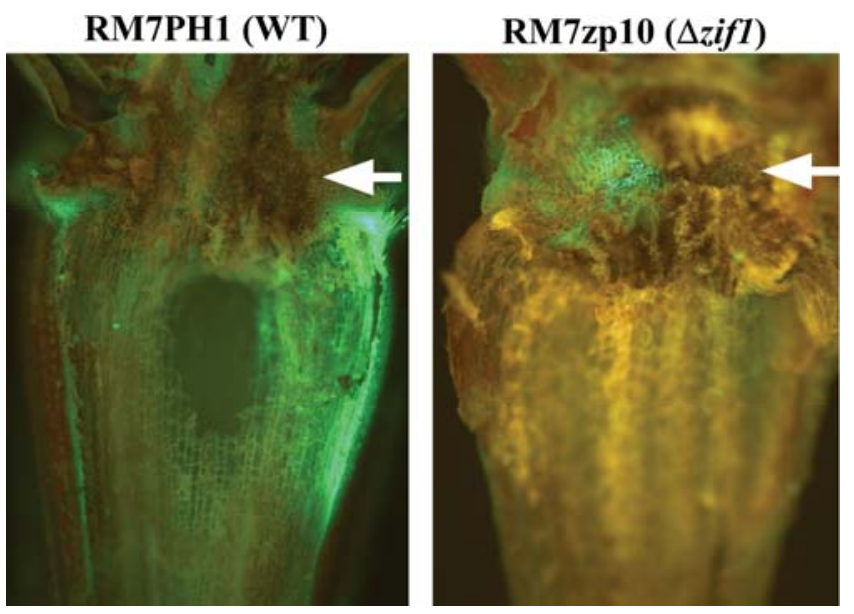

Fig. 5. Rachises from wheat heads inoculated with strains RM7PH1 (wild type [WT]) and RM7ZP10 ( $\Delta z i f 1)$ were dissected and examined under an epifluorescence microscope 5 days postinoculation. Arrows marked the site where the inoculated spikelet was removed. Hyphal growth represented as green fluorescent protein signals was visible in rachis tissues from wheat heads inoculated with RM7PH1 but not RM7zip10. 
When the $\triangle$ Mozifl mutant (MAT1-1) was crossed with the wild-type strain Guy11 (MAT1-2), mature perithecia with long beaks protruding from the surface were formed on the Guy11 side of the confrontation zone after incubation for 3 to 4 weeks (Fig. 7A). Ascospore progeny were isolated from these perithecia (Guy11 as the female), suggesting that MoZIF1 is dispensable for male fertility. However, no perithecia with long necks were observed on the mutant side of the confrontation zone (Fig. 7A). After removing aerial hyphae, immature perithecia were observed in these areas in which the $\Delta$ Mozifl mutant was mated as the female. These perithecia were pigmented but failed to produce long necks (Fig. 7A). Perithecia of the $\Delta$ Mozif1 mutant also were smaller than those of the wild type (Fig. 7B), and sterile (Fig. 7C). Therefore, MoZIF1 is required for late stages of perithecium development and the production of asci and ascospores (Fig. 7B).

\section{Complementation of the $\triangle$ Mozif1 mutant with ZIF1.}

To further test whether ZIFI and MoZIF1 share similar biological functions, we transformed the $\mathrm{P}_{\mathrm{ZIF} 1}-Z I F 1$-eGFP fusion into the $\triangle$ Mozifl mutant. Transformant MFC1 (Table 2) was identified by PCR with primers RGF and NGR to contain the ZIF1-eGFP construct. In infection assays with rice seedlings, it had increased virulence compared with the $\Delta$ Mozifl mutant. The number of blast lesions formed by MFC1 was similar to that of the wild type (Fig. 6), indicating that the $F$. graminearum ZIF1 gene functionally complemented the defects of the M. oryzae $\Delta$ Mozifl mutant in plant infection. However, transformant MFC1, like $F$. graminearum NP18 ( $\triangle$ zifl/ZIF1-eGFP), lacked detectable GFP signals in conidia, vegetative hyphae, appressoria, and infectious hyphae (data not shown).

\section{Genes regulated by $Z I F 1$ in liquid cultures.}

The $F$. graminearum whole-genome GeneChip (Guldener et al. 2006) was used for microarray analysis. In comparison with the wild type, 214 and 328 genes were down- and upregulated, respectively, more than fivefold in the $\Delta$ zifl mutant (Supplementary Tables 1 and 2). Among the downregulated genes, more than $60 \%$ encode hypothetical proteins with unknown biological functions (Supplementary Fig. 4). The second largest Munich Information Center for Protein Sequences (MIPS) category (Mewes et al. 2002) is related to metabolism (20.5\%). Of these genes, $20(9.56 \%)$ are involved in secondary metabolism (MIPS subcategory 01.20$)$. Many genes belonging to MIPS category 20 (cellular transport, 12.4\%) and 32 (defense and virulence, $7.65 \%$ ) also were downregulated in the $\Delta z i f 1$ mutant. Some of them may be involved in plant infection. Among the upregulated genes, approximately 57 and $24 \%$ encode hypothetical proteins and proteins involved in metabolism, respectively. In all, 39 genes involved in ribosome biogenesis (subcategory 12.01) have increased expression levels in the $\Delta$ zifl mutant. Only one gene belonging to this subcategory was downregulated.

The gene with the most significantly reduced expression level in mutant ZP10 was FGSG_01767, which is predicted to encode a cytochrome $\mathrm{P} 450$ monooxygenase similar to pisatin demethylase of Nectria haematococca (George et al. 1998). Its expression also was increased during plant infection (Guldener et al. 2006). If this gene plays a role in detoxifying plant defensive compounds in F. graminearum, its downregulation of 230-fold may be related to the reduced virulence of the $\Delta z$ ifl mutant. Along with the same line, two other putative cytochrome P450 monooxygenase genes, FGSG_03260 and FGSG_03264, also were downregulated more than fivefold in the mutant. Other significantly downregulated genes with possible functions in plant infection include FGSG_06554 and FGSG_09352, which encode a putative catalase and a membrane protein similar to Pth11 in M. oryzae (DeZwaan et al. 1999), respectively.
Interestingly, four of the top six downregulated genes (more than 30-fold reduction) in mutant ZP10 were FGSG_03932 to FGSG_03936. Unfortunately, most of the genes belonging to this putative cluster encode conserved hypothetical proteins, which is not helpful to predict its biological function. Several additional gene clusters were identified among these genes with more than fivefold downregulation in the $\Delta z i f 1$ mutant (Supplementary Table 3). One of them is the aurofusarin synthesis cluster (Frandsen et al. 2006; Kim et al. 2008), suggesting that ZIFI positively regulates aurofusarin biosynthesis in $F$. graminearum. One cluster consists of genes from FGSG_7820 to FGSG_7825. Most of them encode conserved hypothetical proteins unique to filamentous fungi. Some of them may be important for plant infection or sexual reproduction in $F$. graminearum. Interestingly, three downregulated genes, FGSG_01298, FGSG_04894, and FGSG_12978, are homologous to fungal genes involved in selfrecognition or vegetative incompatibility.

To verify the microarray data, we selected the following genes for qRT-PCR analysis: FGSG_02087.3 (putative TfdA family oxidoreductase), FGSG_03935 (short-chain alcohol dehydrogenase), FGSG_03936 (succinate semialdehyde dehydrogenase), FGSG_07822 (major facilitator MirA), FGSG_13098 (putative fungal specific transcription factor), FGSG_0393 (Pth11-like receptor), FGSG_01767 (pisatin demethylase), FGSG_03120 (diacylglycerol pyrophosphate phosphatase), FGSG_03710 (NADH-oxidase), FGSG_04587 (WD40-repeat protein), and FGSG_06554 (catalase). All except for FGSG_ 03710 were confirmed by qRT-PCR to be significantly downregulated in the $\Delta z$ ifl mutant (Fig. 8).

\section{DISCUSSION}

The ZIF1 gene disrupted in REMI mutant M7 encodes a relatively large protein (561 amino acids) with only one known functional domain, the b-ZIP domain. Results from BlastP
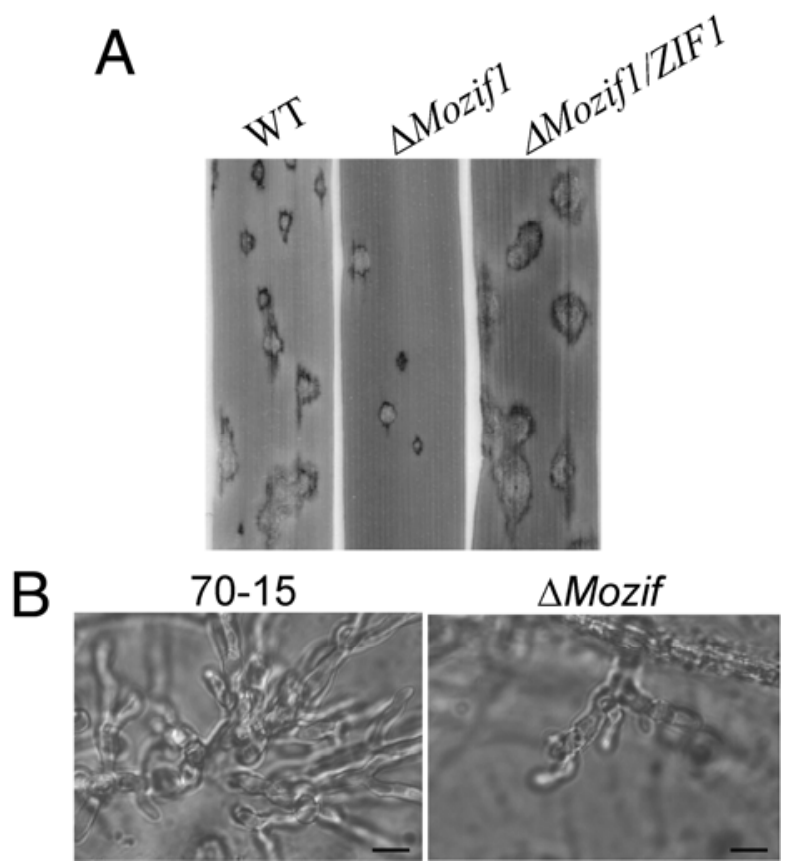

Fig. 6. Infection and penetration assays with the $\Delta$ Mozif1 mutant. A, Rice leaves sprayed with conidia $\left(1 \times 10^{5}\right.$ conidia/ml $)$ from the wild type $(\mathrm{WT})$ 70-15, $\Delta$ Mozif1 mutant, and $\triangle$ Mozifl/ZIF1 complemented transformant MFC1. Typical leaves were photographed 7 days postinoculation. B, Penetration assays with onion epidermal cells. In comparison with the WT strain, the $\Delta$ Mozifl mutant had reduced growth of infectious hyphae in penetrated plant cells $48 \mathrm{~h}$ postinoculation. Bar $=10 \mu \mathrm{m}$. 
searches indicate that ZIF1 is specific to filamentous ascomycetes. Its orthologs are well conserved over the entire protein in the class Sordariomycetes. Surprisingly, one of the maize full-length cDNA clone (GenBank number ACR36092) is highly similar to ZIF1 (38\% identity; e value $=7 \mathrm{e}^{-70}$ ). Because some fungi, such as $F$. verticillioides, could grow endophytically in corn plants, we used the nucleotide sequence of ACR36092 to search different databases. It has no perfect match with any predicted genes in sequenced fungal genomes but shares the highest similarity (79\% identity) with one expressed sequence tag from Penicillium marneffei (GenBank number XM_002146056). Therefore, if ACR36092 is from an endophyte present in tissues used for constructing maize cDNA libraries, this fungus is likely a Eurotiomycete that has not been sequenced.

In $F$. graminearum, the disease index of the $\Delta z$ ifl mutant was less than 1 , which is consistent with its defects in spreading from inoculated floret to the rachis 5 dpi (Fig. 5). ZIFI may play a critical role in invading through the scission zone to the rachis and other spikelets. Because DON is an important virulence factor in F. graminearum (Bai et al. 2002), reduced production of DON in the $\Delta z i f 1$ mutant may be related to its defects in plant infection. In the foliar pathogen $M$. oryzae, the $\Delta M o z i f 1$ mutant penetrated plant cells but had reduced invasive growth, which may be directly responsible for fewer and gen- erally smaller lesions formed by the mutant. Although $F$. graminearum and $M$. oryzae differ in infection mechanisms, the ZIF1 orthologs are conserved in these two fungi for plant infection processes after the initial colonization. It is possible

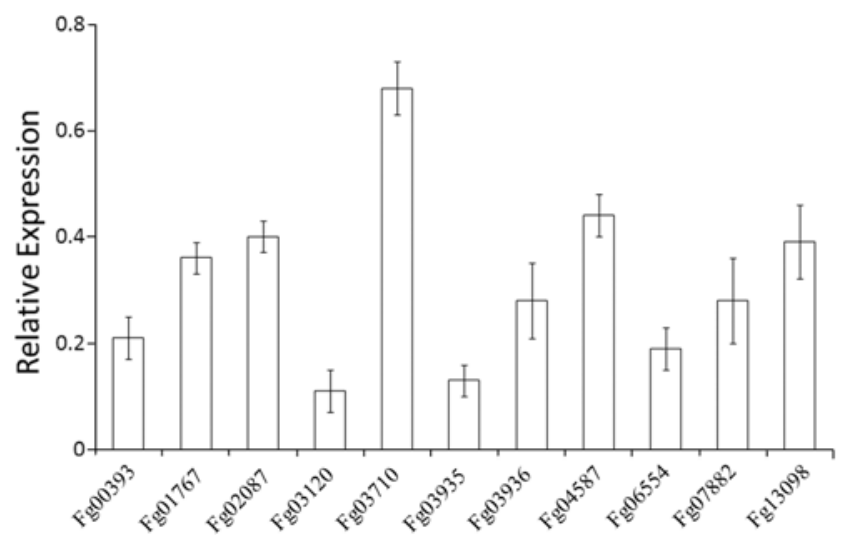

Fig. 8. Quantitative reverse-transcription polymerase chain reaction assays for the expression of selected genes in the $\Delta z i f 1$ mutant. After normalizing with $F g A C T 1$, the relative expression level of each gene in the $\Delta z i f 1 \mathrm{mu}-$ tant was presented as fold changes in comparison with that of the wild type (normalized to the value 1). Mean and standard deviation were calculated with data from three biological replicates.
A

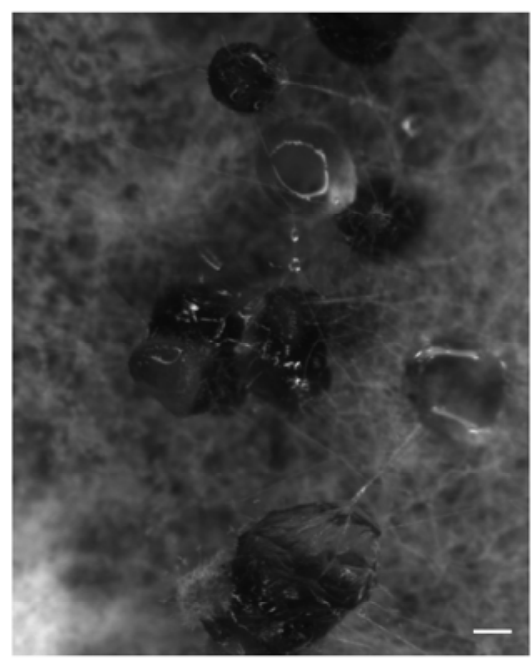

B

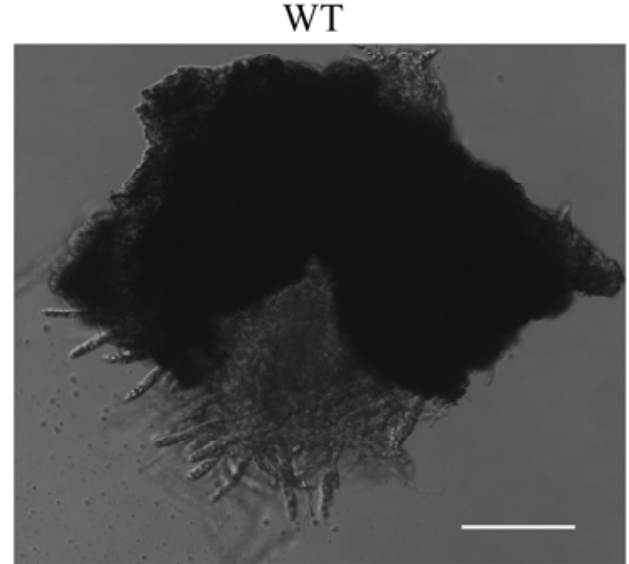

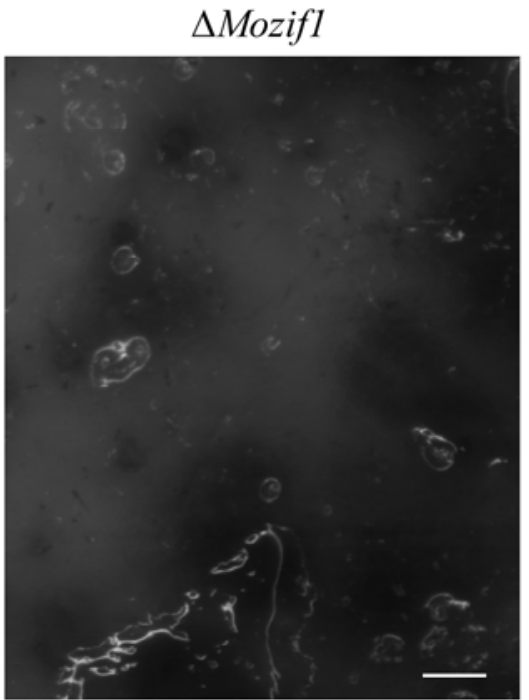

$\Delta$ Mozif1

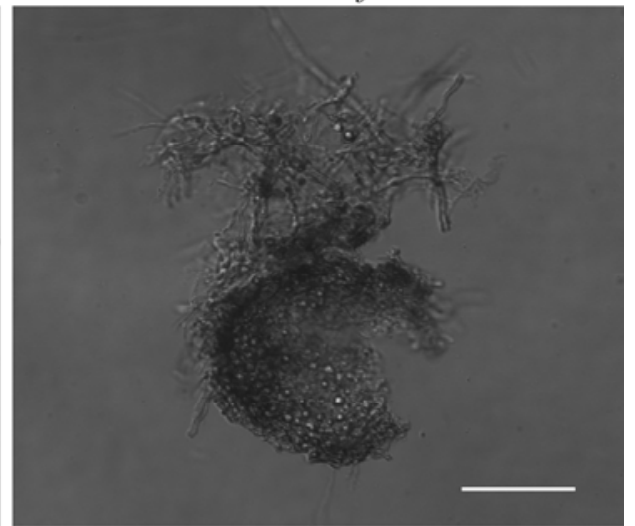

Fig. 7. Defects of the $\Delta$ Mozif1 mutant in sexual reproduction when crossed with the wild-type (WT) strain Guy11. A, Close-up view of 4-week-old mating cultures on the Guy11 (WT, left) or $\Delta$ Mozif1 mutant (right) side of the confrontation zone where each strain was mated as the female. Long beaks produced by WT perithecia protruded from the colony surface. For the mutant culture, aerial hyphae were removed to observe smaller perithecia that were pigmented but blocked in the beak formation inside the medium. B, Typical perithecia from mating zones where Guy 11 or the $\Delta M o z i f 1$ mutant was mated as the female. Asci and ascospores were only visible in WT perithecia. Bar $=50 \mu \mathrm{m}$. 
that the Zif1 transcription factor regulates subsets of genes that are important for fungus-plant interactions during invasive growth or overcoming plant defensive compounds, such as reactive oxygen species (ROS) and phytoalexins. The $\Delta z$ ifl mutant had increased sensitivity to $\mathrm{H}_{2} \mathrm{O}_{2}$ and a reduced expression level of one putative catalase gene. In yeast, Yap1 is a bZIP transcription factor regulating responses to oxidative stress (Delaunay et al. 2000). The Yap1 ortholog FGSG_08800 has not been characterized in $F$. graminearum. In Ustilago maydis and Alternaria alternata, Yap1 orthologs are important for plant infection (Lin et al. 2009; Molina and Kahmann 2007). However, other transcription factors may be responsible for regulating genes important for detoxifying ROS in planta because the Yap1 ortholog is dispensable for virulence in Cochliobolus heterostrophus (Lev et al. 2005).

In infection assays with both wheat heads and corn stalks, the REMI mutant M7 appeared to be more virulent than zifl mutant ZP10 (Fig. 2). DON production also was higher in mutant M7 than in ZP10 (Table 1). Because the insertion site of pYK37 was close to the $\mathrm{C}$ terminus, the b-ZIP domain and $90 \%$ of the amino acid sequence of the Zif1 protein are not affected. It is likely that the disrupted ZIFI allele has some residual activities (not a null allele). In the complemented transformant Bcom9, conidiation, virulence, and DON production were increased significantly in comparison with the $\Delta z$ ifl mutant but were not recovered to the wild-type level (Table 1), indicating that a positional effect may affect the expression and function of the ectopically integrated ZIFI gene.

In the $\Delta z i f 1$ mutant, DON production and the expression of many TRI genes were reduced. Microarray analysis revealed that a number of other gene clusters that involved secondary metabolism were downregulated in the $\Delta z i f 1$ mutant, including the aurofusarin biosynthetic gene cluster. Therefore, ZIF1 may be involved in the global regulation of secondary metabolism in $F$. graminearum. One cluster consists of genes from FGSG_7820 to FGSG_7825. Most of them encode conserved hypothetical proteins unique to filamentous fungi. Approximately half of the genes downregulated in the $\Delta$ zifl mutant have unknown functions. It is possible that some of them are important pathogenicity factors in $F$. graminearum.

ZIF1 also plays a critical role in sexual reproduction. In $F$. graminearum, a homothallic fungus, the $\Delta$ zifll mutant was sterile on selfing cross plates $(\Delta z i f 1 \times \Delta z$ if 1$)$. However, unlike other female sterile mutants in $F$. graminearum, such as the gpmk1, mgv1, FBP1, and Gzsyn2 mutants (Han et al. 2007;
Hong et al. 2010; Hou et al. 2002; Jenczmionka et al. 2003), the $\Delta$ zifl mutant still formed small, dark-pigmented perithecia. In ZIF1 ( 9 ) $\times \Delta z i f 1$ ( $\left.{ }^{*}\right)$ outcrosses, fertile perithecia were produced and $\Delta$ zifl1 progeny were identified, indicating that ZIFI is dispensable for ascospore viability and male fertility. Similar phenomenon was observed in $M$. oryzae, a heterothallic fungus that has weak female fertility or the tendency to lose female fertility under laboratory conditions (Xu et al. 2007; Zeigler 1998). The $\Delta$ Mozifl mutant was fertile when mated as the male. When mated as the female, the $\Delta$ Mozifl mutant produced small, sterile perithecia without long necks (Fig. 7). Therefore, unlike other genes known to be related to female fertility in M. oryzae, such as MPSI and MGBI (Nishimura et al. 2003; Xu et al. 1998), MoZIF1 is dispensable for protoperithecium formation and initial perithecium development but essential for ascosporogenesis and perithecium maturation.

Our results indicate that the ZIFI orthologs play a femalespecific role in ascus and ascospore formation in a homothallic and a heterothallic member of order Sordariomycetes. To our knowledge, no other genes with similar functions in sexual reproduction have been reported in filamentous ascomycetes. For the transvection phenomenon in Neurospora crassa, the asm-1 mutant is defective in ascospore development as either the male or female (Aramayo and Metzenberg 1996). It is most likely that MoZIF1 functions before or during fertilization. Protoperithecia of the $\Delta$ Mozifl mutant may be defective in fertilization. However, it is also possible that small, pigmented perithecia were developed from mutant protoperithecia after fertilization. MoZIF1 may be essential for postfertilization events in developing perithecia, such as dikaryotic hyphal growth and crozier formation. Because the mating defects of the $\Delta$ Mozifl mutant were only observed when it was mated as the female, if MoZIF1 indeed functions postfertilization then $M$. oryzae must be able to distinguish whether the $\Delta M o z i f 1 \mathrm{mu}-$ tant was mated as the male or female in the $\triangle M o z i f 1+M o Z I F 1$ dikaryotic ascogenous hyphae or $\triangle$ Mozifl MoZIF1 diploid crosiers. In the dikaryon or diploid stage, the function of the MoZIF1 allele from the female cannot be replaced by the MoZIF1 allele from the male. In plants and animals, only the maternal or paternal allele of imprinted genes is expressed and functional (Reik and Walter 2001). The female-specific function of MoZIF1 suggests that it may be regulated by a mechanism similar to genetic imprinting in higher eukaryotes. Therefore, it will be important to determine the regulation and biological function of ZIFI and its orthologs in postfertilization events during sexual reproduction in filamentous ascomycetes.

Table 3. Polymerase chain reaction primers used in this study

\begin{tabular}{ll}
\hline Primer & \multicolumn{1}{c}{ Sequence $\left.\mathbf{( 5}^{\prime} \mathbf{-} \mathbf{3}^{\prime}\right)^{\mathbf{a}}$} \\
\hline BTF1F & TAAAGCGTCGTCATCCTCAG \\
BTF2R & GACCTCCACTAGCTCCAGCCAAGCCATTGGCGATGCCAGAGAATC \\
BTF3F & GAATAGAGTAGATGCCGACCGAAAGGGCATACACTAAGCGC \\
BTF4R & TGGCCAACTAATGGCTCATC \\
BTN-1F & TTATCGACGCTGCTGTTCTC- \\
BTN-2R & ACAGGTCCATGGTAAGCAAC \\
bZP1F & ACTCAGGTACCACCATCCGTAACCGTAAAC \\
bZP2R & TAGTAGGTACCTGAGATGTGTCGTGTAGACC \\
GFPNAT/F & GGCGAATTGGGTACTCAAATTGGTACCATCCGTAACCGTAAAC \\
GFPNAT/R & GAACAGCTCCTCGCCCTTGCTCACCAGGTCCATGGTAAGCAAC \\
GFP27/F & CGTAGGAACCCAATCTTCAAAATGTCGGCTCCTGGCCAGAATAA \\
GFP27/R & GAACAGCTCCTCGCCCTTGCTCACCAGGTCCATGGTAAGCAAC \\
ZIF1NGF & CGACTCACTATAGGGCGAATTGGGTACTCAAATTGGGAGCGGTGGACTTGATAA \\
ZIF1NGR & CACCACCCCGGTGAACAGCTCCTCGCCCTTGCTCACCAGGTCCATGGTAAGCAAC \\
ZIF1 RGF & CAGATCTTGGCTTTCGTAGGAACCCAATCTTCAAAATGTCGGCTCCTGGCCAGAATAA \\
BZP1A/R & GAGAATGAAGGTGAGGAGAGCTTCTTGCCCTCCTCGCTA \\
BZP1B/F & TAGCGAGGAGGGCAAGAAGCTCTCCTCACCTTCATTCTC \\
BZP1B/R & GAACAGCTCCTCGCCCTTGCTTTACAGGTCCATGGTAAGCAAC \\
\hline
\end{tabular}

\footnotetext{
${ }^{\text {a }}$ Restriction enzyme sites introduced into the primers are in italic and nucleotide sequences from the $h p h$ gene are underlined.
} 


\section{MATERIALS AND METHODS}

Fungal strains and culture conditions.

The F. graminearum wild-type strain PH-1 (NRRL 31084) and transformants generated in this study (Table 2) were routinely maintained on V8 juice agar plates, cultured on carrot agar plates for sexual reproduction, and grown in liquid CMC medium for conidiation (Cappellini and Peterson 1965; Hou et al. 2002; Trail et al. 2003). Protoplast preparation and fungal transformation were performed as described (Hou et al. 2002). $\mathrm{CM}$ with hygromycin B at $250 \mu \mathrm{g} / \mathrm{ml}$ or geneticin at 250 $\mu \mathrm{g} / \mathrm{ml}$ (Sigma-Aldrich, St. Louis) was used for selection of transformants. The nitl mutant 11622 was used to cross with the $\Delta z i f 1$ mutant as described (Hou et al. 2002). Ascospore progeny were assayed for growth on $\mathrm{CM}$ agar plates with hygromycin $\mathrm{B}$ at $250 \mu \mathrm{g} / \mathrm{ml}, \mathrm{CM}$ with $1 \% \mathrm{KClO}_{3}$, and minimal medium with $1 \% \mathrm{NaNO}_{3}$ as the sole nitrogen source (Ding et al. 2009; Seong et al. 2006). For testing sensitivities to various stresses, fungal growth was assayed after incubation at $25^{\circ} \mathrm{C}$ for 3 days on $\mathrm{CM}$ plates with $1 \mathrm{M}$ sorbitol, $0.7 \% \mathrm{NaCl}$ (wt/vol), Congo red at $200 \mu \mathrm{g} / \mathrm{ml}, 0.01 \%$ SDS (wt/vol), Calcofluor white at $200 \mu \mathrm{g} / \mathrm{ml}$, or $0.08 \% \mathrm{H}_{2} \mathrm{O}_{2}$.

The $M$. oryzae wild-type and mutant strains were cultured on oatmeal agar plates as described (Park et al. 2006). Transformants were selected on TB3 with hygromycin B at 250 $\mu \mathrm{g} / \mathrm{ml}$ or zeocin at $300 \mu \mathrm{g} / \mathrm{ml}$ (Invitrogen, Carlsbad, CA, U.S.A.). Mating and genetic crosses were performed as described (Crawford et al. 1986).

\section{Generation of the $\Delta z$ zif1 mutant.}

To generate the ZIF1 gene replacement constructs using the split-marker approach (Catlett et al. 2003), 0.83-kb upstream and $0.85-\mathrm{kb}$ downstream fragments were amplified with primer pairs BTF1F/BTF2R and BTF3F/BTF4R (Table 3), respectively. The $h y$ and $y g$ fragments of the hygromycin phosphotransferase $(h p h)$ gene were amplified with primers HYGF, HYR, YGF, and HYGR as described (Mehrabi et al. 2008; Zhou et al. 2010). After transformation, hygromycin-resistant transformants were screened by PCR with primers BTN-1F and BTN-2R (Table 3) and further characterized by Southern blot analysis. For complementation assays, a 3.9-kb fragment containing the ZIF1 gene was amplified with primers bZP1F and bZP2R (Table 3) and cloned into pHZ100 (Bluhm et al. 2007). The resulting construct pJY01 (Fig. 1A) was transformed into protoplasts of the $\Delta$ zifl mutant ZP10.

\section{Generation of GFP fusion constructs.}

Primers ZIF1NGF and ZIF1NGR (Table 3) were used to amplify the ZIF1 ORF plus 1.5 -kb upstream promoter region. The resulting PCR products were cotransformed into Saccharomyces cerevisiae XK1-25 with XhoI-digested pFL2 vector, which was generated by replacing the $h p h$ gene on the vector backbone of pDL2 with the geneticin-resistance marker (Bourett et al. 2002; Bruno et al. 2004). The $\mathrm{P}_{\mathrm{ZIF} 1}$-ZIF1-eGFP fusion construct was identified by PCR with primers ZIP1NF/R and confirmed by sequencing analysis. The same yeast in vivo recombination approach was used to generate the $\mathrm{P}_{\mathrm{RP} 27}$-ZIF1-eGFP construct. Both fusion constructs were transformed into protoplasts of the $\Delta z$ ifl mutant.

\section{Construction of the $Z I F 1^{\Delta \mathrm{bZIP}}$ allele.}

To generate the $Z I F 1^{\Delta \mathrm{bIIP}}$ allele (deleted from amino acid residues 276 to 339 ), the ZIF1 fragments upstream and downstream from the b-ZIP domain were amplified with primer pairs GFPNAT/F-BZPA/R and BZP1B/F-BZP1B/R (Table 3), respectively. The resulting PCR products were co-transformed with XhoI-digested pKB04 into yeast strain XK1-25 (Bruno et al.
2004). The $Z I F 1^{\Delta b Z I P}$ construct recovered from $\operatorname{Trp}^{+}$yeast transformants was confirmed by sequencing analysis and transformed into mutant ZP10.

\section{The $\Delta M o z i f 1$ deletion mutant in M. oryzae.}

The upstream and downstream flanking sequences of $M g Z I F 1$ were amplified and ligated with the $h p h$ cassette released from pCX63 (Zhao et al. 2004). With the ligation product as the template, the $M g Z I F 1$ gene replacement construct was amplified with primers $\mathrm{bBm}$ and $\mathrm{bEI}$ and transformed into the wild-type strain 70-15 as described (Xu and Hamer 1996). Putative $M g Z I F 1$ gene-replacement mutants were screened by PCR and further confirmed by Southern blot analyses. To complement the $M$. oryzae mutant with the $F$. graminearum ZIF1 gene, the $\mathrm{P}_{\mathrm{ZIF} 1}$-ZIF1-eGFP fusion construct was transformed into the $\triangle M$ ozifl mutant. The resulting zeocin-resistant transformants were confirmed by PCR to contain the ZIF1eGFP fusion construct.

\section{Plant infection assays.}

Conidia harvested from 5-day-old CMC cultures of $F$. graminearum strains were resuspended to $10^{6}$ conidia/ml in $0.01 \%$ (vol/vol) Tween 20. Six-week-old wheat plants of cv. Norm were drop inoculated with conidium suspensions as described (Gale et al. 2002; Kang and Buchenauer 1999). Diseased spikelets in each wheat head were counted 14 dpi to estimate disease indices as described (Gale et al. 2002; Seong et al. 2006). Infection assays with corn silks were performed as described (Seong et al. 2005). For corn stalk infection assays, sterile wooden toothpicks were briefly soaked in conidium suspensions and used to inoculate mature plants of corn cv. Pioneer 2375 as described (Zhou et al. 2010). Stalk rot symptoms were examined $14 \mathrm{dpi}$.

For M. oryzae, conidia harvested from 10-day-old oatmeal cultures were used for appressorium formation, penetration of onion epidermal cells, and rice infection assays as described (Park et al. 2006; Xue et al. 2002; Zhao and Xu 2007). Twoweek-old seedlings of rice cv. Nipponbare were used for spray and injection inoculation.

\section{Assay for DON production.}

Diseased wheat kernels were harvested from inoculated spikelets 14 dpi and assayed for DON as described (Bluhm et al. 2007). DON production also was assayed with cultures grown in the defined medium with $0.2 \%$ agmatine as described (Gardiner et al. 2009a; Zhou et al. 2010).

\section{Microarray analysis.}

Conidia harvested from 5-day-old CMC cultures were resuspended in $100 \mathrm{ml}$ of $\mathrm{CM}$ to $10^{6}$ conidia/ml. After incubation at $25^{\circ} \mathrm{C}$ for $16 \mathrm{~h}$, germlings were collected by filtration and used for RNA isolation with the TRIzol reagent (Invitrogen). For both the wild type and the $\Delta$ zifl mutant, RNA was isolated from three biological replicates. For each sample, $5 \mu \mathrm{g}$ of total RNA was labeled with the Affymetrix eukaryotic RNA labeling kit (Affymetrix, Santa Clara, CA, U.S.A.). Hybridization and washing of the Fusarium GeneChip (Guldener et al. 2006) were performed at the Purdue Core Genomics Facility with standard Affymetrix procedures. Hybridization signals were scanned with a GeneChip GCS 3000 scanner (Affymetrix). The resulting CEL files were processed with software MAS5.0 (Affymetrix) and further analyzed with GeneSpring GX V7.2 (Agilent Technologies, Santa Clara, CA, U.S.A.).

\section{qRT-PCR analyses.}

RNA was isolated with the Trizol reagent (Invitrogen) and used for cDNA synthesis with the StrataScript QPCR cDNA 
synthesis kit (Stratagene, La Jolla, CA, U.S.A.) following the instructions provided by the manufacturer. Primers TubQF and TubQR (Bluhm et al. 2007) were used to amplify the $\beta$-tubulin gene TUB2 of $F$. graminearum. PCR was performed with a Stratagene MX3000 system as described (Zhou et al. 2010). After normalizing the expression of tested genes with $T U B 2$, relative changes in gene expression levels were calculated by the comparative cycle threshold method (Applied Biosystems, Foster City, CA, U.S.A.). For each gene, qRT-PCR data from three biological replicates were used to calculate the mean and standard deviation.

\section{ACKNOWLEDGMENTS}

We thank K. Seong and J. Yao for assistance in generating the mutants and microarray analysis, Y. Dong for DON detection, and L. Dunkle and S. Goodwin for critical reading of this manuscript. This work was supported by grants to J.-R. Xu and H. C. Kistler from the U.S. Wheat and Barley Scab Initiative and the National Research Initiative of the United States Department of Agriculture Cooperative State Research, Education, and Extension Service (numbers 2007-35319-102681 and 2008-3560418800).

\section{LITERATURE CITED}

Alexander, N. J., Proctor, R. H., and McCormick, S. P. 2009. Genes, gene clusters, and biosynthesis of trichothecenes and fumonisins in Fusarium. Toxin Rev. 28:198-215.

Aramayo, R., and Metzenberg, R. L. 1996. Meiotic transvection in fungi. Cell 86:103-113.

Audenaert, K., Callewaert, E., Hofte, M., De Saeger, S., and Haesaert, G. 2010. Hydrogen peroxide induced by the fungicide prothioconazole triggers deoxynivalenol (DON) production by Fusarium graminearum. BMC Microbiol. 10:112.

Bai, G. H., and Shaner, G. 2004. Management and resistance in wheat and barley to Fusarium head blight. Annu. Rev. Phytopathol. 42:135-161.

Bai, G. H., Desjardins, A. E., and Plattner, R. D. 2002. Deoxynivalenolnonproducing Fusarium graminearum causes initial infection, but does not cause disease spread in wheat spikes. Mycopathologia 153:91-98.

Baldwin, T. K., Urban, M., Brown, N., and Hammond-Kosack, K. E. 2010. A role for topoisomerase I in Fusarium graminearum and F. culmorum pathogenesis and sporulation. Mol. Plant-Microbe Interact. 23:566-577.

Bluhm, B. H., Zhao, X., Flaherty, J. E., Xu, J. R., and Dunkle, L. D. 2007. $R A S 2$ regulates growth and pathogenesis in Fusarium graminearum. Mol. Plant-Microbe Interact. 20:627-636.

Boddu, J., Cho, S., Kruger, W. M., and Muehlbauer, G. J. 2006. Transcriptome analysis of the barley-Fusarium graminearum interaction. Mol. Plant-Microbe Interact. 19:407-417.

Bourett, T. M., Sweigard, J. A., Czymmek, K. J., Carroll, A., and Howard, R. J. 2002. Reef coral fluorescent proteins for visualizing fungal pathogens. Fungal Genet. Biol. 37:211-220.

Bruno, K. S., Tenjo, F., Li, L., Hamer, J. E., and Xu, J. R. 2004. Cellular localization and role of kinase activity of $P M K 1$ in Magnaporthe grisea. Eukaryot. Cell 3:1525-1532.

Cappellini, R., and Peterson, J. L. 1965. Macroconidium formation in submerged cultures by a non-sporulating strain of Gibberella zeae. Mycologia 57:962-966

Catlett, N. L., Lee, B., Yoder, O. C., and Turgeon, B. G. 2003. Split-marker recombination for efficient targeted deletion of fungal genes. Fungal Genet. Newsl. 50:9-11.

Chao, C. C. T., and Ellingboe, A. H. 1991. Selection for mating competence in Magnaporthe grisea pathogenic to rice. Can. J. Bot. 69:2130-2134.

Crawford, M. S., Chumley, F. G., Weaver, C. G., and Valent, B. 1986. Characterization of the heterokaryotic and vegetative diploid phases of Magnaporthe grisea. Genetics 114:1111-1129.

Cuomo, C. A., Guldener, U., Xu, J.-R., Trail, F., Turgeon, B. G., Di Pietro, A., Walton, J. D., Ma, L., Baker, S. E., Rep, M., Adam, G., Antoniw, J., Baldwin, T., Calvo, S., Chang, Y., DeCaprio, D., Gale, L. R., Gnerre, S., Goswami, R. S., Hammond-Kosack, K., Harris, L. J., Hilburn, K., Kennell, J. C., Kroken, S., Magnuson, J. K., Mannhaupt, G., Mauceli, E., Mewes, H., Mitterbauer, R., Muehlbauer, G., Münsterkötter, M., Nelson, D., O’Donnell, K., Ouellet, T., Qi, W., Quesneville, H., Roncero, M. I. G., Seong, K., Tetko, I. V., Urban, M., Waalwijk, C., Ward, T. J., Yao, J., Birren, B. W., and Kistler, H. C. 2007. The Fusarium graminearum genome reveals a link between localized polymorphism and pathogen specialization. Science 317:1400-1402.
Delaunay, A., Isnard, A., and Toledano, M. B. 2000. $\mathrm{H}_{2} \mathrm{O}_{2}$ sensing through oxidation of the Yap1 transcription factor. EMBO (Eur. Mol. Biol. Organ.) J. 19:5157-5166.

Desjardins, A. E. 2003. Gibberella from A (venaceae) to Z (eae). Annu. Rev. Phytopathol. 41:177-198.

DeZwaan, T. M., Carroll, A. M., Valent, B., and Sweigard, J. A. 1999. Magnaporthe grisea Pth11p is a novel plasma membrane protein that mediates appressorium differentiation in response to inductive substrate cues. Plant Cell 11:2013-2030.

Ding, S. L., Mehrabi, R., Koten, C., Kang, Z. S., Wei, Y. D., Seong, K. Y., Kistler, H. C., and Xu, J. R. 2009. Transducin beta-like gene FTL1 is essential for pathogenesis in Fusarium graminearum. Eukaryot. Cell 8:867-876.

Escher, D., Bodmer-Glavas, M., Barberis, A., and Schaffner, W. 2000. Conservation of glutamine-rich transactivation function between yeast and humans. Mol. Cell. Biol. 20:2774-2782.

Frandsen, R. J. N., Nielsen, N. J., Maolanon, N., Sorensen, J. C., Olsson, S., Nielsen, J., and Giese, H. 2006. The biosynthetic pathway for aurofusarin in Fusarium graminearum reveals a close link between the naphthoquinones and naphthopyrones. Mol. Microbiol. 61:1069-1080.

Gale, L. R., Chen, L. F., Hernick, C. A., Takamura, K., and Kistler, H. C. 2002. Population analysis of Fusarium graminearum from wheat fields in eastern China. Phytopathology 92:1315-1322.

Gardiner, D. M., Kazan, K., and Manners, J. M. 2009a. Nutrient profiling reveals potent inducers of trichothecene biosynthesis in Fusarium graminearum. Fungal Genet. Biol. 46:604-613.

Gardiner, D. M., Osborne, S., Kazan, K., and Manners, J. M. 2009b. Low $\mathrm{pH}$ regulates the production of deoxynivalenol by Fusarium graminearum. Microbiology 155:3149-3156.

George, H. L., Hirschi, K. D., and VanEtten, H. D. 1998. Biochemical properties of the products of cytochrome P450 genes (PDA) encoding pisatin demethylase activity in Nectria haematococca. Arch. Microbiol. 170:147-154.

Goswami, R. S., and Kistler, H. C. 2004. Heading for disaster: Fusarium graminearum on cereal crops. Mol. Plant Pathol. 5:515-525.

Guldener, U., Seong, K. Y., Boddu, J., Cho, S. H., Trail, F., Xu, J. R., Adam, G., Mewes, H. W., Muehlbauer, G. J., and Kistler, H. C. 2006 Development of a Fusarium graminearum Affymetrix GeneChip for profiling fungal gene expression in vitro and in planta. Fungal Genet. Biol. 43:316-325.

Han, Y. K., Kim, M. D., Lee, S. H., Yun, S. H., and Lee, Y. W. 2007. A novel F-box protein involved in sexual development and pathogenesis in Gibberella zeae. Mol. Microbiol. 63:768-779.

Hong, S. Y., So, J., Lee, J., Min, K., Son, H., Park, C., Yun, S. H., and Lee, Y. W. 2010. Functional analyses of two syntaxin-like SNARE genes, $G z S Y N 1$ and $G z S Y N 2$, in the ascomycete Gibberella zeae. Fungal Genet. Biol. 47:364-372.

Hou, Z. M., Xue, C. Y., Peng, Y. L., Katan, T., Kistler, H. C., and Xu, J. R. 2002. A mitogen-activated protein kinase gene (MGV1) in Fusarium graminearum is required for female fertility, heterokaryon formation, and plant infection. Mol. Plant-Microbe Interact. 15:1119-1127.

Jenczmionka, N. J., and Schafer, W. 2005. The Gpmk1 MAP kinase of Fusarium graminearum regulates the induction of specific secreted enzymes. Curr. Genet. 47:29-36.

Jenczmionka, N. J., Maier, F. J., Losch, A. P., and Schafer, W. 2003. Mating, conidiation and pathogenicity of Fusarium graminearum, the main causal agent of the head-blight disease of wheat, are regulated by the MAP kinase gpmk1. Curr. Genet. 43:87-95.

Jiang, L. H., Yang, J. R., Fan, F. Y., Zhang, D. J., and Wang, X. L. 2010. The Type 2C protein phosphatase FgPtc1p of the plant fungal pathogen Fusarium graminearum is involved in lithium toxicity and virulence. Mol. Plant Pathol. 11:277-282.

Kang, Z., and Buchenauer, H. 1999. Immunocytochemical localization of Fusarium toxins in infected wheat spikes by Fusarium culmorum Physiol. Mol. Plant Pathol. 55:275-288.

Kim, J. E., Kim, J. C., Jin, J. M., Yun, S. H., and Lee, Y. W. 2008. Functional characterization of genes located at the aurofusarin biosynthesis gene cluster in Gibberella zeae. Plant Pathol. J. 24:8-16.

Kim, J. E., Lee, H. J., Lee, J., Kim, K. W., Yun, S. H., Shim, W. B., and Lee, Y. W. 2009. Gibberella zeae chitin synthase genes, GzCHS5 and $\mathrm{GzCHS7,}$ are required for hyphal growth, perithecia formation, and pathogenicity. Curr. Genet. 55:449-459.

Kimura, M., Tokai, T., Takahashi-Ando, N., Ohsato, S., and Fujimura, M. 2007. Molecular and genetic studies of Fusarium trichothecene biosynthesis: Pathways, genes, and evolution. Biosci. Biotechnol. Biochem. 71:2105-2123.

Lee, S. H., Han, Y. K., Yun, S. H., and Lee, Y. W. 2009a. Roles of the glyoxylate and methylcitrate cycles in sexual development and virulence in the cereal pathogen Gibberella zeae. Eukaryot. Cell 8:1155-1164.

Lee, S. H., Lee, J., Lee, S., Park, E. H., Kim, K. W., Kim, M. D., Yun, S. 
H., and Lee, Y. W. 2009b. GzSNF1 is required for normal sexual and asexual development in the ascomycete Gibberella zeae. Eukaryot. Cell 8:116-127.

Lev, S., Hadar, R., Amedeo, P., Baker, S. E., Yoder, O. C., and Horwitz, B. A. 2005. Activation of an AP1-like transcription factor of the maize pathogen Cochliobolus heterostrophus in response to oxidative stress and plant signals. Eukaryot. Cell 4:443-454.

Lin, C. H., Yang, S. L., and Chung, K. R. 2009. The Yap1 homolog-mediated oxidative stress tolerance is crucial for pathogenicity of the necrotrophic fungus Alternaria alternata in citrus. Mol. Plant-Microbe Interact. 22:942-952.

Mehrabi, R., Ding, S., and Xu, J. R. 2008. MADS-box transcription factor Mig1 is required for infectious growth in Magnaporthe grisea. Eukaryot. Cell 7:791-799.

Mewes, H. W., Frishman, D., Güldener, U., Mannhaupt, G., Mayer, K., Mokrejs, M., Morgenstern, B., Münsterkötter, M., Rudd, S., Weil, B. 2002. MIPS: A database for genomes and protein sequences. Nucleic Acids Res. 30:31-34.

Molina, L., and Kahmann, R. 2007. An Ustilago maydis gene involved in $\mathrm{H}_{2} \mathrm{O}_{2}$ detoxification is required for virulence. Plant Cell 19:2293-2309.

Nishimura, M., Park, G., and Xu, J. R. 2003. The G-beta subunit MGB1 is involved in regulating multiple steps of infection-related morphogenesis in Magnaporthe grisea. Mol. Microbiol. 50:231-243.

Oide, S., Moeder, W., Krasnoff, S., Gibson, D., Haas, H., Yoshioka, K., and Turgeon, B. G. 2006. NPS6, encoding a nonribosomal peptide synthetase involved in siderophore-mediated iron metabolism, is a conserved virulence determinant of plant pathogenic ascomycetes. Plant Cell 18:2836-2853.

Park, G., Xue, C., Zhao, X., Kim, Y., Orbach, M., and Xu, J. R. 2006. Multiple upstream signals converge on an adaptor protein Mst50 to activate the PMK1 pathway in Magnaporthe grisea. Plant Cell 18:2822-2835.

Proctor, R. H., Hohn, T. M., and McCormick, S. P. 1995. Reduced virulence of Gibberella zeae caused by disruption of a trichothecene toxin biosynthetic gene. Mol. Plant-Microbe Interact. 8:593-601.

Reik, W., and Walter, J. 2001. Genomic imprinting: Parental influence on the genome. Nat. Rev. Genet. 2:21-32.

Schmale, D. G., Shah, D. A., and Bergstrom, G. C. 2005. Spatial patterns of viable spore deposition of Gibberella zeae in wheat fields. Phytopathology 95:472-479.

Seong, K., Hou, Z. M., Tracy, M., Kistler, H. C., and Xu, J. R. 2005. Random insertional mutagenesis identifies genes associated with virulence in the wheat scab fungus Fusarium graminearum. Phytopathology 95:744750 .

Seong, K., Li, L., Hou, Z. M., Tracy, M., Kistler, H. C., and Xu, J. R. 2006. Cryptic promoter activity in the coding region of the HMG-CoA rediactase gene in Fusarium graminearum. Fungal Genet. Biol. 43:3441.

Seong, K. Y., Pasquali, M., Zhou, X., Song, J., Hilburn, K., McCormick, S. P., Dong, Y., Xu, J. R., and Kistler, H. C. 2009. Global gene regulation by Fusarium transcription factors Tri6 and Tri10 reveals adaptations for toxin biosynthesis. Mol. Microbiol. 72:354-367.

Trail, F. 2009. For blighted waves of grain: Fusarium graminearum in the postgenomics era. Plant Physiol. 149:103-110.

Trail, F., Xu, H. X., Loranger, R., and Gadoury, D. 2002. Physiological and environmental aspects of ascospore discharge in Gibberella zeae (anamorph Fusarium graminearum). Mycologia 94:181-189.

Trail, F., Xu, J. R., San Miguel, P., Halgren, R. G., and Kistler, H. C. 2003. Analysis of expressed sequence tags from Gibberella zeae (anamorph Fusarium graminearum). Fungal Genet. Biol. 38:187-197.

Trail, F., Gaffoor, I., and Vogel, S. 2005. Ejection mechanics and trajectory of the ascospores of Gibberella zeae (anamorph Fuarium graminearum). Fungal Genet. Biol. 42:528-533.

Urban, M., Mott, E., Farley, T., and Hammond-Kosack, K. 2003. The Fusarium graminearum MAP1 gene is essential for pathogenicity and development of perithecia. Mol. Plant Pathol. 4:347-359.

Walter, S., Nicholson, P., and Doohan, F. M. 2010. Action and reaction of host and pathogen during Fusarium head blight disease. New Phytol. 185:54-66.

Xu, J. R., and Hamer, J. E. 1996. MAP kinase and cAMP signaling regulate infection structure formation and pathogenic growth in the rice blast fungus Magnaporthe grisea. Genes Dev. 10:2696-2706.

Xu, J. R., Staiger, C. J., and Hamer, J. E. 1998. Inactivation of the mitogen-activated protein kinase $M p s 1$ from the rice blast fungus prevents penetration of host cells but allows activation of plant defense responses. Proc. Natl. Acad. Sci. USA 95:12713-12718.

Xu, J. R., Zhao, X., and Dean, R. A. 2007. From genes to genomes; a new paradigm for studying fungal pathogenesis in Magnaporthe oryzae. Adv. Genet. 57:175-218.

Xue, C. Y., Park, G., Choi, W. B., Zheng, L., Dean, R. A., and Xu, J. R. 2002. Two novel fungal virulence genes specifically expressed in appressoria of the rice blast fungus. Plant Cell 14:2107-2119.

Yu, H. Y., Seo, J. A., Kim, J. E., Han, K. H., Shim, W. B., Yun, S. H., and Lee, Y. W. 2008. Functional analyses of heterotrimeric G protein $\mathrm{G}$ alpha and $\mathrm{G}$ beta subunits in Gibberella zeae. Microbiology 154:392-401.

Zeigler, R. S. 1998. Recombination in Magnaporthe grisea. Annu. Rev. Phytopathol. 36:249-275.

Zhao, X. H., and Xu, J. R. 2007. A highly conserved MAPK-docking site in Mst7 is essential for Pmk1 activation in Magnaporthe grisea. Mol. Microbiol. 63:881-894

Zhao, X. H., Xue, C., Kim, Y., and Xu, J. R. 2004. A ligation-PCR approach for generating gene replacement constructs in Magnaporthe grisea. Fungal Genet. Newsl. 51:17-18.

Zhou, X. Y., Heyer, C., Choi, Y. E., Mehrabi, R., and Xu, J. R. 2010. The CID1 cyclin C-like gene is important for plant infection in Fusarium graminearum. Fungal Genet. Biol. 47:143-151.

\section{AUTHOR-RECOMMENDED INTERNET RESOURCE}

PLEXdb database: www.plexdb.org 